\title{
Using low-fix rate GPS telemetry to expand estimates of ungulate reproductive success
}

\author{
Nathan D. Hooven ${ }^{1 *} \mathbb{D}$, Kathleen E. Williams' ${ }^{1}$, John T. Hast ${ }^{2}$, Joseph R. McDermott ${ }^{2}$, R. Daniel Crank², \\ Gabe Jenkins ${ }^{2}$, Matthew T. Springer ${ }^{1}$ and John J. Cox ${ }^{1}$
}

\begin{abstract}
Background: Population parameters such as reproductive success are critical for sustainably managing ungulate populations, however obtaining these data is often difficult, expensive, and invasive. Movement-based methods that leverage Global Positioning System (GPS) relocation data to identify parturition offer an alternative to more invasive techniques such as vaginal implant transmitters, but thus far have only been applied to relocation data with a relatively fine (one fix every $<8 \mathrm{~h}$ ) temporal resolution. We employed a machine learning method to classify parturition/ calf survival in cow elk in southeastern Kentucky, USA, using 13-h GPS relocation data and three simple movement metrics, training a random forest on cows that successfully reared their calf to a week old.

Results: We developed a decision rule based upon a predicted probability threshold across individual cow time series, accurately classifying $89.5 \%$ (51/57) of cows with a known reproductive status. When used to infer status of cows whose reproductive outcome was unknown, we classified 48.6\% (21/38) as successful, compared to $85.1 \%$ (40/47) of known-status cows.
\end{abstract}

Conclusions: While our approach was limited primarily by fix acquisition success, we demonstrated that coarse collar fix rates did not limit inference if appropriate movement metrics are chosen. Movement-based methods for determining parturition in ungulates may allow wild life managers to extract more vital rate information from GPS collars even if technology and related data quality are constrained by cost.

Keywords: Reproduction, Parturition, Vital rates, GPS telemetry, Ungulates, Movement

\section{Background}

Wildlife managers must obtain reliable estimates of vital rates to characterize and quantify populations to inform predictive models [1-3]. Furthermore, population parameters are critical in understanding the relationship of species to their environment $[4,5]$ including the effects of habitat $[6,7]$ and harvest management [8-10] on demography and population dynamics. Assessing the relative importance of specific vital rates for animal populations allows wildlife managers to implement conservation

*Correspondence: nathan.d.hooven@gmail.com

1 Department of Forestry and Natural Resources, University of Kentucky, Lexington, $\mathrm{KY}, \mathrm{USA}$

Full list of author information is available at the end of the article and management actions $[1,11,12]$; however, collecting sufficient quality and quantity of demographic data to robustly inform population models is often difficult due to budgetary and logistical constraints.

Ungulate population management heavily relies on obtaining reproductive parameters and neonatal survival estimates [13-16] which may be difficult. Established field methods to obtain these data included opportunistic sampling of reproductive organs from harvested females [17], pregnancy determination via palpation $[18,19]$ or serological analysis [20-22], characterization of juvenile/adult ratios from visual observation [21, 23-25], and radio-marking and monitoring of juveniles [26-28]. Vaginal implant transmitters (VITs) have become a reliable field method for determining the timing and location of 
ungulate parturition [29-31]. VITs allow researchers to rapidly deploy to parturition sites and mark neonates for survival studies, thereby reducing potential bias inherent in other methods that often rely on opportunistic captures of older individuals [32, 33]. For example, fitting gestating females with VITs can allow for the identification of stillbirths and the estimation of fetal survival that opportunistic capture efforts can miss or not provide $[15,34]$. Fetal survival is very difficult to assess in freeranging animals [35] but nonetheless bridges a critical gap between pregnancy rate and offspring survival rate (Fig. 1). Additionally, occurrence of fetal loss and stillbirth are related to the mother's condition and can be indicative of extrinsic environmental factors [14, 35-39]. Failure to incorporate an estimate of fetal survival into population models may lead to overestimation of the proportion of sexually mature females that produce and recruit offspring in a given biological year.

While the use of VITs has the potential to improve estimates of neonatal and fetal survival, their invasive nature and the cost of deploying them [40-43] have prompted researchers to use advances in Global Positioning System (GPS) telemetry to develop methods that identify changes in movement and space use metrics to determine parturition and birth sites [41, 44, 45]. Changes in movement patterns prior to and after parturition are well-documented in cervids, including moose (Alces alces) [46-48], mule deer (Odocoileus hemionus) [43, 49], caribou (Rangifer tarandus) [41, 44, 50], and elk (Cervus canadensis) [51, 52].

Several analytical methods have leveraged these movement patterns to infer ungulate parturition. Approaches that examined single variables were developed first and focused on movement distances [41, 52]. DeMars et al. [41] defined caribou movement rate thresholds based on population- and individuallevel distributions to identify movement depressions likely associated with parturition. Although others later applied this method [44, 50, 53], a single-variable approach may not be as useful in other ungulate species with different life histories and movement behavior [45]. Machine learning algorithms offer a more flexible technique that can accommodate large numbers of variables that may exhibit complex, non-linear relationships with response variables [54]. Random forest classification is a machine learning method that employs decision trees in an ensemble to classify observations into groups based on predictor variables $[55,56]$ that has been successfully used to infer parturition in elk, roe deer (Capreolus capreolus), and mouflon (Ovis

\section{a}
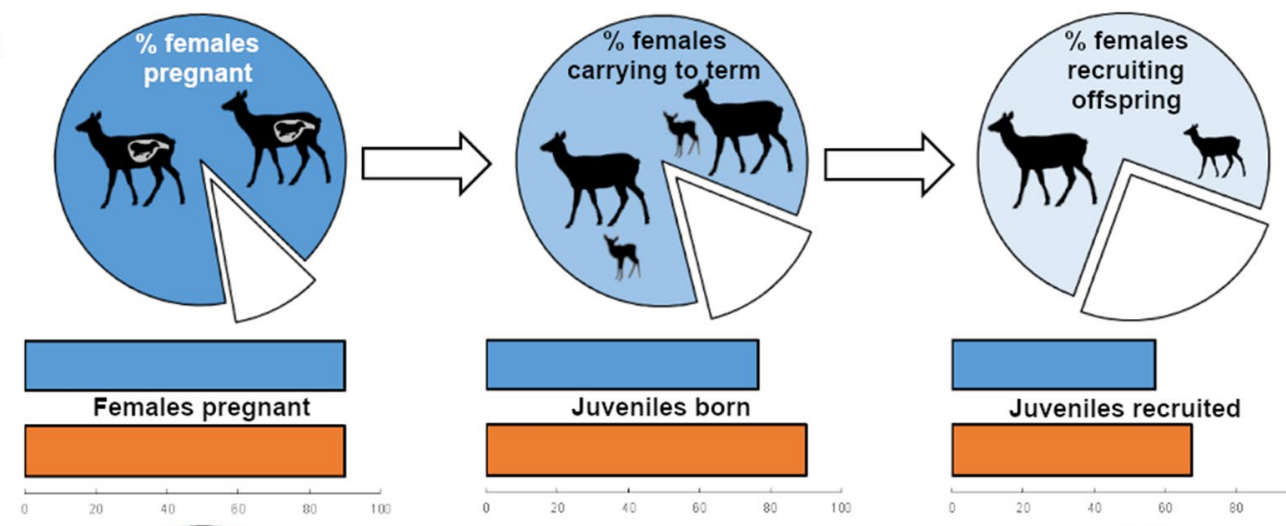

b
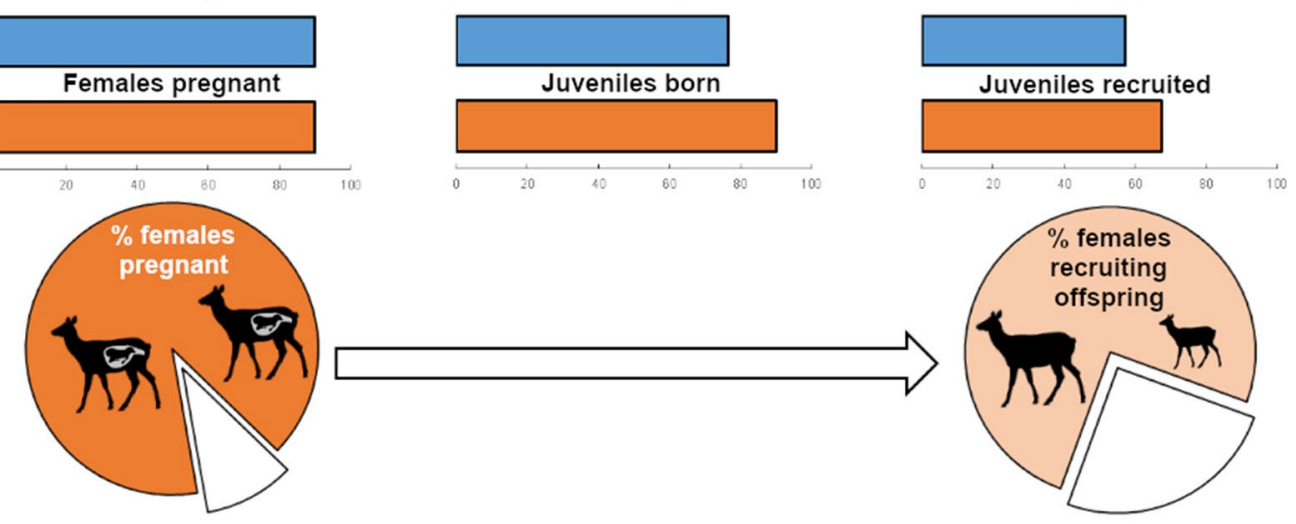

Fig. 1 Diagram illustrating the importance of fetal survival in determining reproductive success in a uniparous mammal. Both scenarios (a, b) begin with a hypothetical population consisting of 100 reproductive-age females. Scenario $\mathbf{a}$ differs from $\mathbf{b}$ in that it accounts for a subset of pregnant females that did not carrying their offspring to term due to fetal resorption, abortion, or stillbirth, and thus the colored section of the pie chart in the second panel represents fetal survival. The percent of females that recruit their offspring after 1 year is represented in the third panel. Bar graphs indicate the number of individuals remaining after each stage 
gmelini) [45, 57]. Both studies highlighted the importance of using a suite of predictors to identify changes in behavior that may indicate parturition in several ungulate species.

The advent of these techniques has the potential to expand estimates of parturition success and facilitate neonate capture without the use of VITs, however their usefulness is largely determined by the temporal resolution and location accuracy of the GPS transmitter used. To our knowledge, none of the published studies that used GPS telemetry and a movement-based approach to determine ungulate parturition $(n=20)$ report a fix rate scheme coarser than one fix every $8 \mathrm{~h}$ (range $=0.08-8 \mathrm{~h} ; \mu \pm \mathrm{SE}=3.16 \pm 0.40 \mathrm{~h} ; n=29$ schemes; Additional file 1: Table S1). One study by Nobert et al. [58] tested the accuracy of the DeMars et al. [41] approach with decreasing fix rate up to $24 \mathrm{~h}$, but due to sharp decreases in accuracy only retained data from collars with $\leq 6 \mathrm{~h}$ fix rates. Given the widespread use of "budget", low-temporal resolution GPS telemetry collars for basic survival monitoring in ungulate management programs, and the time and financial cost of current methods (e.g., VITS, classification counts), it may be useful for agency biologists and managers to extract additional information (e.g., parturition success) from lower frequency relocation data.

Rocky Mountain elk (C. c. nelsoni; hereafter "elk") were translocated to southeastern Kentucky, USA, beginning in 1997, and have since established and spread throughout the 16-county Kentucky Elk Restoration Zone (KERZ). Current estimates from the Kentucky Department of Fish and Wildlife Resources (KDFWR) place the population at $>15,000$ individuals, making it the largest east of the Mississippi River [59]. Population expansion of elk and an increase in annual harvest highlight the need for up-to-date estimates of demographic parameters to inform population models [60]. In an effort to update vital rate estimates used in the state's elk population model, we initiated a study of reproductive rates and neonatal survival using "natal-linked" GPS collar systems with paired VITs [31].

Using confirmed parturition events and calf survival data from these natal-linked GPS collars, we developed a movement-based method to determine the probability of parturition and early calf survival during the calving season (15 May-15 Jul) in southeastern Kentucky. We then applied this method to cows fitted with traditional low-fix rate GPS collars to predict parturition/calf survival status. Our goal was to assess the feasibility of using low-fix rate GPS telemetry to identify parturition, thus providing the opportunity to obtain an estimate of initial reproductive success without using VITs or visual observation of a female with a calf.

\section{Methods}

\section{Study area}

We conducted this study across the KERZ, a $16,802 \mathrm{~km}^{2}$ area in southeastern Kentucky, USA, which is part of the Cumberland Plateau physiographic region and is characterized by steep mountain ridges, dendritic drainages, and narrow valley bottoms [61]. The primary land cover type is mixed-mesophytic forest, while surface coal mining and the subsequent reclamation process has led to widespread patches of gentler topography dominated by forb/graminoid meadows and shrublands. Elk within the KERZ are generally highly associated with early-successional habitat created by the mine reclamation process as well as the open-forest edge and high interspersion of cover types in these landscapes [62].

\section{Elk capture}

Cow elk were captured as part of a larger study on adult reproductive rates and calf survival in the KERZ. Adult cows (age $\geq 1.5$ years) were captured using aerial netgunning (Native Range Capture Services, Elko, NV, USA and Helicopter Wildlife Services, Austin, TX, USA) and ground trapping using modified Clover traps [63] during January and February of 2020 and 2021. Net-gunned cows were blindfolded, hobbled, and moved to a central workup location, while Clover-trapped cows were processed inside the traps. Most animals received a $2 \mathrm{~mL}$ dose of either butorphanol tartrate $(27.3 \mathrm{mg} / \mathrm{mL})$-medetomidine $(10.9 \mathrm{mg} / \mathrm{mL})$-azaperone $(9.1 \mathrm{mg} / \mathrm{mL})$ (BAM; ZooPharm Inc., Laramie, WY, USA) or nalbuphine $\mathrm{HCl}(40 \mathrm{mg} /$ $\mathrm{mL})$-azaperone $(10 \mathrm{mg} / \mathrm{mL})$-medetomidine $(10 \mathrm{mg} /$ mL) (NalMed-A; Wildlife Pharmaceuticals, Windsor, CO, USA) [64-66] intramuscularly to induce chemical immobilization, while those that exhibited elevated body temperatures $\left(>\sim 40{ }^{\circ} \mathrm{C}\right)$ were not anesthetized or ultrasounded. We fit a GPS telemetry collar (LifeCycle Pro or GlobalstarTrack Pro; Lotek Wireless, Newmarket, ON, Canada; or Vertex Plus GPS; Vectronic Aerospace, Berlin, Germany) to each cow, initially programmed to provide a location fix every $13 \mathrm{~h}$. For cows fit with Vectronic collars, we conducted rectal ultrasonography using a portable ultrasound unit (Ibex Pro; E.I. Medical Imaging, Loveland, $\mathrm{CO}$ ) to confirm pregnancy in the field. We then inserted a paired VIT, which was programmed to communicate with the collar via ultra-high frequency (UHF) to send a mortality beacon when its recorded temperature and activity level drop beneath a threshold $\left(<\sim 34{ }^{\circ} \mathrm{C}\right.$ and 0 activity level). Additionally, we collected a 20-mL blood sample from each cow and isolated serum for pregnancy-specific protein B (PSPB) assays (BioPRYN; Herd Health Diagnostics, Pullman, WA, USA) to confirm pregnancy status at the time of capture. We then reversed immobilization using a combination of $0.5 \mathrm{~mL}$ 
of naltrexone $\mathrm{HCl}(50 \mathrm{mg} / \mathrm{mL})$ and $4 \mathrm{~mL}$ of atipamezole $(25 \mathrm{mg} / \mathrm{mL})$ and released cows at the work-up site.

\section{VIT and calf investigation}

For cows instrumented with VITs, we remotely monitored their body temperature and activity from capture until the VIT was expelled each year remotely via Vectronic Aerospace's (Berlin, Germany) provided online interface INVENTA [67] and software GPS PLUS X 10.7.1, as well as with alarm notifications sent through email and SMS. We attempted to investigate all expulsion events as soon as possible, including those outside of the putative calving season (15 May-15 Jul; $91.3 \%$ of confirmed parturition events), to document possible abortions or stillbirths. Once we received an expulsion notification, we homed to the expelled VIT with veryhigh frequency (VHF) telemetry and attempted to locate either a fetus or a live calf to confirm parturition success and collar the calf for a concurrent calf survival project. Once a calf was collared, we monitored it remotely via the paired separation tag onboard its expandable neonate collar (Vectronic Aerospace, Berlin, Germany), which communicates with the cow's GPS collar via UHF signal and sends regular status messages to INVENTA and GPS PLUS X. If we did not receive a "not separated" message within $\sim 24 \mathrm{~h}$ of the previous message, we assumed that the cow had not returned to its calf during this period and thus attempted to monitor the calf's collar via VHF telemetry to detect a potential mortality signal. If the collar was in mortality mode, we homed to it and determined whether the signal was a result of a slipped collar or a calf mortality. We searched the immediate and surrounding areas for pieces of the calf carcass, blood, hair, and sign of other animals [13], and documented the condition of the carcass and consumption patterns to determine likely cause of death [26]. We attempted to investigate all calf mortality events with $\sim 12 \mathrm{~h}$.

\section{GPS relocation data processing and movement metric calculation}

We performed all spatial data processing and analysis in program R 3.6.2 [68] via the RStudio environment (RStudio, Boston, MA, USA). For both Vectronic and Lotek GPS collars we retained relocations from 14 May to 22 Jul for each year, removed missed or improbable fixes (e.g., those outside the study area) as well as those with a dilution of precision (DOP) $>10$ to ensure reasonable positional accuracy [69], and then transformed all data from latitude/longitude to universal transverse Mercator (UTM) easting and northing coordinates (zone 17S) to facilitate generation of planar distance metrics in $\mathrm{R}$ package 'sp' version 1.4-1 [70]. Next, we created tracks for each cow in R package 'amt' version 0.1.3 [71] and generated bursts of relocations that only included those that were taken $13 \mathrm{~h}$ ( $\pm 2 \mathrm{~h}$ tolerance) apart from one another. Note that for most of the study period, Vectronic collars were programmed to attempt a fix every seven hours, thus this resampling resulted in a fix every $\sim 14 \mathrm{~h}$.

We chose step length (Euclidean distance between successive relocations; $m$ ) as our first movement metric as it is widely used in the literature to predict parturition timing for ungulates $[41,43,45,52]$. Specifically, we used the mean step length across a 3-day period, centered on each focal day (i.e., the days during the study period that we trained and tested the model on) and including both the day before and after (sl.3 day). We used this instead of calculating total or daily average movement rates [41] because of our low-resolution fix rate and the potential for low fix acquisition success (especially with Lotek collars). We expected cows to exhibit a contraction in mean step length associated with localization surrounding parturition, without a pronounced movement immediately prior [51, 52], as confirmed parturient cows in our study tended to not alter their movement patterns before parturition (Additional file 1: Fig. S1, Table S2).

Because parturient cow elk tend to maintain contracted movement patterns only for a short period post-parturition ( $\sim$ days) [51], and because we recognized that fix acquisition failures could exacerbate problems related to low fix rates (i.e., small volume of relocation data with which to calculate movement metrics), we also chose to include the mean step length for the 7 day period after the date of parturition (sl.post7) as our second movement metric. Although this lag in the cow's return to typical movement rates is not ubiquitous in elk across North America [72], we documented a lag of $\sim 10$ days in our study (Fig. 2), suggesting that the inclusion of this variable is likely informative to when cows gave birth.

We used minimum convex polygons (MCPs) to measure space use across surrounding focal periods during the calving season. Space use is well-understood to contract surrounding and post-parturition in ungulates $[73,74]$, and short-term spatial localization associated with parturition has been leveraged to identify timing and location of birth $[75,76]$. MCPs represent a simple method to outline all relocations within a time period, and fitting them along a rolling window allows for identification of localization events [77]. We predicted that parturient cows would localize due to the limited mobility of their neonates, and thus would exhibit less space use within the parturition window than outside. We used the $R$ package 'adehabitatHR' version 0.4 .16 [78] to fit $100 \%$ MCPs to relocations within 11-day moving windows, centered upon a focal day an including 5 days before and after (mcp). We chose 11 days for our moving window to ensure we could calculate MCPs 


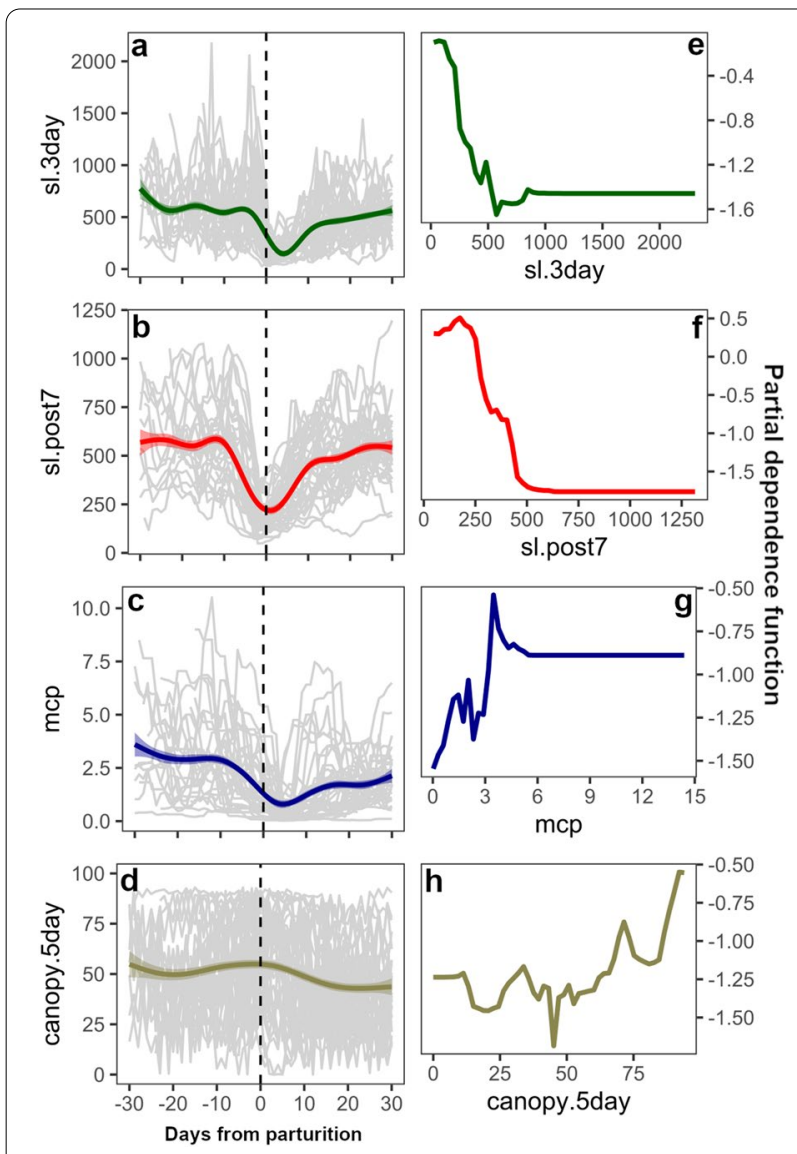

Fig. 2 Distribution and partial dependence of three variables used to build a random forest classification model. $\mathbf{a}-\mathbf{d}$ The distribution of the three movement/space use variables around parturition. Colored lines are generalized additive model predictions for all pooled elk data, and gray lines represent time series for each individual. e- $\mathbf{h}$ The partial dependence of the random forest model on each spatial variable, across the range of values observed in the testing dataset

for as many focal days as possible for collars with low fix success, while also being able to identify shifts in space use at a meaningful temporal scale.

Finally, we included percent canopy cover as a landscape predictor variable as this was identified as an important correlate of parturition site selection in Kentucky elk (Hooven et al. in preparation). We downloaded the 30-m spatial resolution 2016 U.S. Forest Service canopy cover raster [79] and clipped it to the KERZ in ArcMap 10.6.1 (ESRI, Redlands, CA, USA). We extracted the canopy cover value for each retained relocation using the extract function in $\mathrm{R}$ package 'raster' version 3.0-12 [80]. We considered 5-day windows for this predictor, and thus calculated the mean percent canopy cover associated with each individual cow's relocations for 2 days prior to the focal day, the focal day, and 2 days after (canopy.5 day).

\section{Model training}

We employed a machine learning approach to determine the probability of the occurrence of parturition leading to early calf survival within a given day, similarly to Marchand et al. [45]. We used the 'randomForest' package version 4.6-14 in R [81] to train a random forest (RF) model with 1000 trees on a dataset from all VIT-instrumented, parturient cows with a confirmed parturition date (our training dataset). To fit the model, we created a binary response variable, attributing a " 1 " to all days during which parturition occurred (parturition windows) and a "0" to all other days (non-parturition windows), and specifying the RF to classify each day in the training dataset as either a " 1 " or a " 0 " as a function of the four predictor variables (sl.3 day, mcp, sl.post7, and canopy.5 day). To ensure that the RF model was balanced (i.e., equivalent number of parturition and non-parturition days) we specified an equal sample size. We extracted out-of-bag predicted probabilities of belonging to group "1" (i.e., the probability of being a parturition day) for each day in the dataset from the fitted model and considered the day with the highest probability to be the predicted day of parturition for each individual.

\section{Model testing}

Once we trained the RF model, we tested it on data from several groups of individuals who differed in reproductive status: (A) confirmed non-parturient cows (those that were either confirmed not to be pregnant in midwinter or that gave birth outside of our defined calving season); (B) cows with unknown parturition status during the calving season (individuals that were confirmed pregnant in mid-winter but were not instrumented with VITs, those confirmed pregnant but who lost their VIT prematurely with no evidence of abortion/stillbirth found, or those confirmed pregnant but whose VIT malfunctioned and precluded identification of a parturition event); and (C) cows who were instrumented with VITs in 2020 and survived through the calving season in 2021 (Table 1).

We tested the RF model on Group A (non-parturient) cows for two reasons: (1) to determine the specificity of our model, or the proportion of correctly identified non-parturient individuals; and (2) to aid in developing a decision rule for parturition determination in Groups $\mathrm{B}$ and $\mathrm{C}$. Marchand et al. [45] used a 1\% quantile of predicted probabilities as a threshold above which parturition was inferred. However, low probabilities were associated with several correctly predicted days in our training dataset, so we decided to examine all individuals in Group A to determine if a threshold exists which correctly discriminates between windows associated with parturition in these training individuals and all 
Table 1 Confirmed and predicted reproductive outcomes for GPS-collared elk cows

\begin{tabular}{|c|c|c|c|c|c|c|c|c|c|c|c|c|}
\hline \multirow[t]{2}{*}{ Outcome } & \multicolumn{3}{|c|}{ VIT-instrumented cows } & \multicolumn{3}{|c|}{ Group B predictions } & \multicolumn{3}{|c|}{ Group C predictions } & \multicolumn{3}{|c|}{ Overall } \\
\hline & 2020 & 2021 & Total & 2020 & 2021 & Total & 2020 & 2021 & Total & 2020 & 2021 & Total \\
\hline \multicolumn{13}{|l|}{ Unused } \\
\hline Not pregnant & 0 & 2 & 2 & & & & & & & 0 & 2 & 2 \\
\hline Cow died & 1 & 1 & 2 & & & & & & & 1 & 1 & 2 \\
\hline Early expulsion & 1 & 2 & 3 & & & & & & & 1 & 2 & 3 \\
\hline VIT malfunction & 2 & 0 & 2 & & & & & & & 2 & 0 & 2 \\
\hline Born outside period & 0 & 2 & 2 & & & & & & & 0 & 2 & 2 \\
\hline$<30$ days of data & & & & 9 & 4 & 13 & & & & 9 & 4 & 13 \\
\hline \multicolumn{13}{|l|}{ Used for calculations } \\
\hline Abortion & 0 & 1 & 1 & & & & & & & 0 & 1 & 1 \\
\hline Stillborn & 0 & 1 & 1 & & & & & & & 0 & 1 & 1 \\
\hline Calf died within 1 week & 2 & 3 & 5 & & & & & & & 2 & 3 & 5 \\
\hline Overall failure & 2 & 5 & 7 & 7 & 3 & 10 & & 7 & 7 & 9 & 8 & 24 \\
\hline Calf survived to 1 week & 19 & 21 & 40 & 7 & 2 & 9 & & 12 & 12 & 26 & 23 & 61 \\
\hline Totals & 21 & 26 & 47 & 14 & 5 & 19 & & 19 & 19 & 35 & 31 & 85 \\
\hline Success rate & 0.905 & 0.808 & 0.851 & 0.500 & 0.400 & 0.474 & & 0.632 & 0.632 & 0.743 & 0.742 & 0.718 \\
\hline
\end{tabular}

Here we consider a "success" to be when an individual gives live birth and rears a calf to at least 1 week old. Individuals not used for calculations include cows determined to be not pregnant via blood test, cows that died before giving birth, cows with early VIT expulsions or malfunctions, cows that gave birth outside the study calving period ( 15 May-15 Jul), and cows for which we received < 30 days of relocation data. Group B consists of cows that were confirmed pregnant via serology in mid-winter but whose parturition/calf survival status were unknown. Group C contains cows that were instrumented with VITs in 2020 and survived to the calving period in 2021; we did not capture these cows again and thus their pregnancy status in 2021 was unknown

windows in non-parturient animals. Consequently, we chose a decision rule based upon (1) a probability threshold and (2) a number of days within a given peak in the probability time series. The resulting rule maximized the overall accuracy of classification without sacrificing either sensitivity or specificity. For both cows we confirmed and predicted as parturient, we considered the day with the highest probability within the time series to be the model-predicted day of parturition. Thus, we defined specificity as the proportion of correctly identified "unsuccessful" cows, sensitivity as the proportion of correctly identified "successful" cows, and accuracy as the combination of these two proportions, or the overall proportion of known-status cows that our approach correctly identified. We assessed the relative contribution of each variable to classification of a given focal day as one during which parturition occurred using the mean decrease in the Gini impurity index implemented in the importance function in 'randomForest' [81]. This measures how the addition of each predictor increases the "purity" of a given decision tree node, i.e., the percentage of observations of a single class [56].

Because we expected individual variation in movement and space use behavior to potentially limit the predictive ability of our approach, we investigated the consistency of behavior for individuals that we monitored for multiple calving seasons (Group C cows). We calculated repeatability ( $\mathrm{R}$ package 'rptR' version 0.9 .22 ; [82]) of each predictor variable for cows whose predicted reproductive status remained the same from 2020 to 2021 as well as those whose status changed. We expected those with the same status to remain consistent in their behavior (i.e., less likely to switch behavioral types from year to year), while those with different statuses to exhibit more intraindividual variation.

\section{Results}

We instrumented 58 cows with Vectronic GPS collars and paired VITs during January and February 2020 $(n=25)$ and $2021(n=33)$. Of these, two cows died before giving birth, three expelled their VITs early and no fetus was recovered, two had VITs malfunction, two were determined to be not pregnant via PSPB assay, one had its collar fail before giving birth, and two cows gave birth outside of the study period (15 May-15 Jul) in 2021. We documented one fetal abortion, one probable stillborn calf, and five neonatal calf mortalities (age $<1$ week; Table 1 ). We confirmed that 39 cows successfully gave birth and reared their calf to $\geq 1$ week of age via calf collar communication with the cow's collar and VHF telemetry when necessary. We censored two individuals from the RF training set due to collar failure and low fix success during the study period, leaving relocation data from 37 individuals with which to train the RF model. We also fit 46 other cows with Lotek GPS collars, and of these, 27 were confirmed pregnant, 19 
were not pregnant. We also censored two cows from Group A in the testing set that did not give birth within the study period due to contracted movements likely associated with meningeal worm (Parelaphostrongylus tenuis) infection.

During the study period (including 1 day before the first focal day and 7 days after the final focal day), we collected 11,219 relocations from 119 individual elk-seasons after filtering and resampling with a mean $( \pm$ SE) of $94.3 \pm 3.4$ relocations per elk-season (range 6-129). Our overall fix acquisition success was $74.5 \%$ (range for individual elkseasons: $4.7-100 \%$ ), but we documented a substantial difference between collar manufacturers across both years (Table 2). Fix success for Vectronic collars was $95.2 \%$ (range: $84.0-100 \%$ ) and only $42.7 \%$ (range: $4.7-96.9 \%$ ) for Lotek collars. Given this wide range of fix success rates, we observed concomitant variation in the number of focal days across the study period for which we were able to calculate movement metrics. This resulted in fewer than the total possible focal days (62) for which the RF model could calculate a predicted probability for many individual collars. Again, while the overall mean number of focal days $( \pm \mathrm{SE})$ was high $(48.7 \pm 1.3$ days), the range was wide (0-62) and means differed markedly between Vectronic $(61.8 \pm 0.07)$ and Lotek collars $(27.8 \pm 3.4)$. Unsurprisingly, fix success and the number of prediction days (days with full predictor variable data that we were able to generate a prediction for) was highly correlated (Spearman's rank correlation; $\rho=0.879 ; p<0.001$ ). Due to sparse relocation data leading to $<30$ prediction days across the study period, we censored six elk-seasons from Group A and 13 from Group B.

Our RF model was reasonably accurate at classifying parturition status across a range of decision rules (Fig. 3). Mean step length for the 7-day period post-parturition (sl.post7) was the most important variable (mean decrease in Gini index: 18.5), followed by mean step length for a 3-day focal period (sl.3 day; 9.2), 11-day MCP (mcp; 5.5), and 5-day canopy cover (canopy.5 day; 3.8 ). Indeed, the partial dependence for mcp peaked at intermediate values, rather than values close to zero as predicted (Fig. 2). We chose to classify individual elk status as parturient/calf lived to $\geq 1$ week if its model-predicted probability time series had a distinct peak at or above a threshold of 0.75 for at least 1 day (for an example, see Fig. 4). We chose this rule to maximize both the sensitivity (proportion of parturient elk correctly classified) and the specificity (proportion of non-parturient cows or those that lost their calf within 1 week correctly classified) and yielded a sensitivity of $91.9 \%$ (34/37), a specificity of $85.0 \%(17 / 20)$, and an overall accuracy of $89.5 \%$ (51/57; Table 3). Using our test data, this approach classified $47.4 \%$ (9/19) of Group B cows (those that were confirmed pregnant during mid-winter, but whose parturition status was unknown) and 63.2\% (12/19) of Group $C$ cows (those instrumented with VITs in 2020) as parturient. This yielded a total predicted success rate of $55.3 \%$ $(21 / 38)$ for cows with unknown parturition/early calf survival status, compared to our confirmed success rate of $85.1 \%$ (40/47) for VIT-instrumented cows; however,

Table 2 Summary of fix success and prediction days for GPS telemetry collars fit to cow elk

\begin{tabular}{|c|c|c|c|c|c|c|c|c|c|}
\hline \multirow[t]{2}{*}{ Collar brand } & \multirow[t]{2}{*}{ Group } & \multirow[t]{2}{*}{ Year } & \multirow[t]{2}{*}{$\mathbf{n}$} & \multicolumn{3}{|c|}{ Fix success } & \multicolumn{3}{|c|}{ Prediction days } \\
\hline & & & & Mean & SE & Range & Mean & SE & Range \\
\hline \multirow[t]{9}{*}{ Vectronic } & \multirow[t]{2}{*}{ Training } & 2020 & 19 & 0.976 & 0.004 & $0.973-1.000$ & 61.842 & 0.086 & $61-62$ \\
\hline & & 2021 & 18 & 0.934 & 0.011 & $0.848-1.000$ & 61.778 & 0.129 & $60-62$ \\
\hline & \multirow[t]{2}{*}{ Group A } & 2020 & 1 & 0.992 & & & 62.000 & & \\
\hline & & 2021 & 10 & 0.928 & 0.016 & $0.840-1.000$ & 61.600 & 0.267 & $60-62$ \\
\hline & \multirow[t]{2}{*}{ Group B } & 2020 & 3 & 0.975 & 0.013 & $0.959-1.000$ & 62.000 & 0.000 & $62-62$ \\
\hline & & 2021 & 2 & 1.000 & 0.000 & $1.000-1.000$ & 62.000 & 0.000 & $62-62$ \\
\hline & Group C & 2021 & 19 & 0.950 & 0.006 & $0.907-1.000$ & 62.000 & 0.000 & $62-62$ \\
\hline & Other & 2021 & 1 & 0.848 & & & 59.000 & & \\
\hline & All & & 73 & 0.952 & 0.005 & $0.840-1.000$ & 61.800 & 0.067 & $59-62$ \\
\hline \multirow[t]{5}{*}{ Lotek } & \multirow[t]{2}{*}{ Group A } & 2020 & 12 & 0.477 & 0.069 & $0.155-0.899$ & 35.364 & 6.625 & $1-62$ \\
\hline & & 2021 & 7 & 0.379 & 0.083 & $0.078-0.651$ & 29.200 & 8.089 & $10-52$ \\
\hline & \multirow[t]{2}{*}{ Group B } & 2020 & 20 & 0.443 & 0.067 & $0.047-0.969$ & 35.412 & 5.599 & $1-62$ \\
\hline & & 2021 & 7 & 0.339 & 0.074 & $0.062-0.543$ & 23.500 & 7.549 & $3-45$ \\
\hline & All & & 46 & 0.427 & 0.038 & $0.047-0.969$ & 27.800 & 3.370 & $0-62$ \\
\hline
\end{tabular}

Summaries are organized by collar brand (Vectronic and Lotek) and by the training or testing group each elk-season belongs to. For final prediction, we censored one Vectronic elk-season from the training set, three Lotek elk-seasons from the Group A testing set, and three Lotek elk-seasons from the Group B testing set due to low fix success 


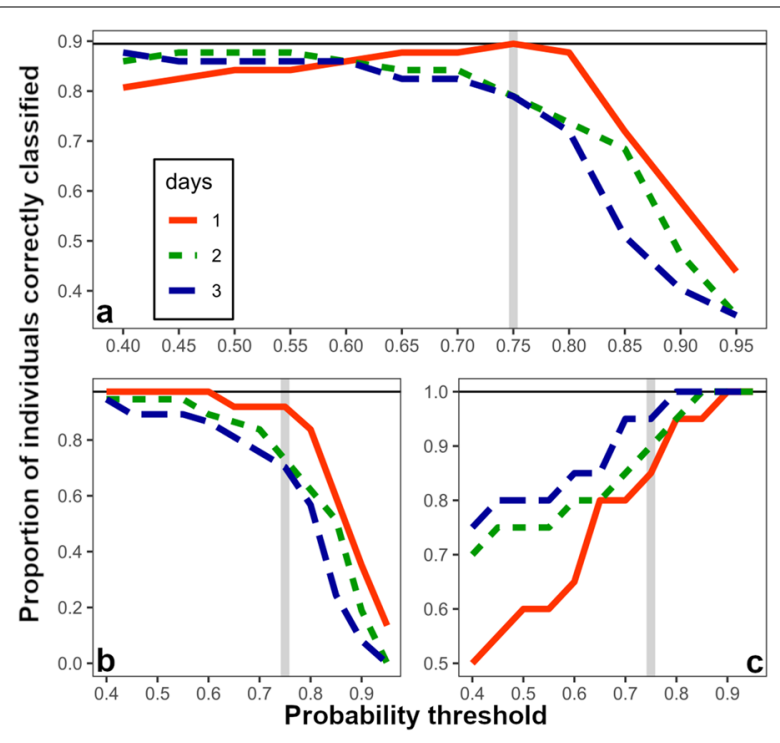

Fig. 3 Plots of the proportion of individual elk whose parturition status was correctly identified (accuracy). Overall classification accuracy (a) combines correct classification of parturient elk used to build the random forest model $(n=37)$ and elk that were either non-parturient or lost their calf within the first week post-parturition, used to test the model $(n=20)$. $\mathbf{b}$ Sensitivity and only includes parturient elk from the training set and $\mathbf{c}$ specificity and only includes non-parturient/calf loss elk from the testing set. Gray lines indicate the chosen decision probability threshold (0.75). Each color/line type indicates the number of days at or above the probability threshold that we considered

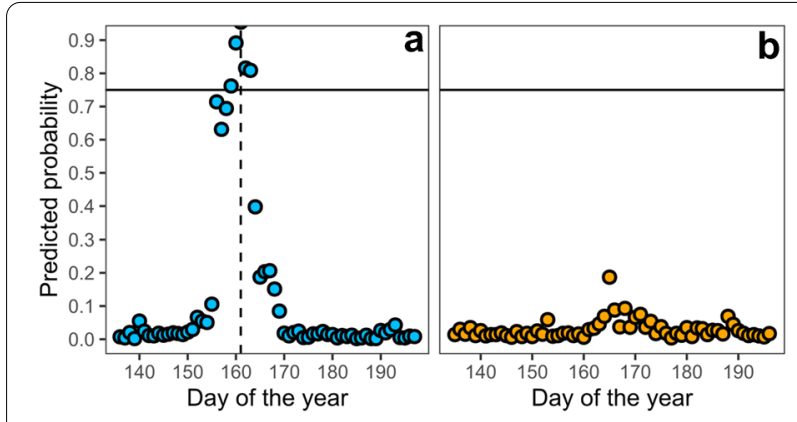

Fig. 4 Comparison of predicted probabilities for a confirmed parturient cow (left) and a barren cow (right). The dashed line is both the predicted and true date of parturition for this individual, while the horizontal lines are the probability threshold used for the decision rule $(0.75)$ note that pregnancy status for the 2020 VIT cows was unknown in 2021. The pooled success rate among confirmed and predicted cows was $71.8 \%$ (61/85; Table 1).

Predicted parturition dates were generally in concordance with confirmed parturition dates [mean $( \pm S E)$ difference: $3.0 \pm 1.19$ days] with only two predictions deviating $>5$ days (Additional file 1: Table S3). The median parturition day of the year for training set cows was 155 (2-3 Jun), while the median for testing set cows was 158 (6-7 Jun). When we included parturition dates for confirmed parturient cows either not included in the training set $(n=5)$ or not classified as parturient by our approach $(n=5)$, the median day of the year for all confirmed cows was 157 (5-6 Jun). Given both confirmed and predicted parturition dates observed in this study, we consider calving to peak the first week of June in Kentucky's elk population (Fig. 5).

We found that cows that were consistent between 2020 and 2021 in their predicted reproductive status had highly repeatable movement behaviors (Fig. 7; Additional file 1: Table S5), for both step length metrics $(R \pm$ SE: $0.83 \pm 0.14$ for sl.3 day and $0.92 \pm 0.08$ for sl.post7) and the 11-day MCP (mcp; $0.788 \pm 0.154$ ) while the behavior of cows with inconsistent predicted status was not repeatable for sl.3 day $(0.0 \pm 0.23)$ and sl.post7 $(0.0 \pm 0.22)$.

\section{Discussion}

We demonstrated the utility of low-fix rate GPS telemetry collars for estimating parturition and early calf survival in elk in Kentucky. We consider our classification approach's accuracy rate $(89.5 \%)$ to be acceptable as it fell within the range (73-100\%) of other published studies that also assessed prediction accuracy [41, 44, 45, 52]. While our results show promise for extracting reproductive information from budget GPS collars, there are several limitations to our approach which likely led to misclassification and thus a lower accuracy rate.

First, fix acquisition success likely limited our inference. Although we only censored seven total individuals across all datasets due to low fix success, it is probable that reduced datasets for individuals we retained led to some misclassification of parturition status. As expected, we documented the lowest fix

Table 3 Sensitivity, specificity, and accuracy, based upon random forest predicted probabilities and a threshold decision rule

\begin{tabular}{|c|c|c|c|c|c|c|c|c|c|}
\hline & \multicolumn{3}{|c|}{ Sensitivity } & \multicolumn{3}{|c|}{ Specificity } & \multicolumn{3}{|c|}{ Accuracy } \\
\hline & 2020 & 2021 & Total & 2020 & 2021 & Total & 2020 & 2021 & Total \\
\hline Correct & 17 & 17 & 34 & 7 & 10 & 17 & 24 & 27 & 51 \\
\hline \multirow[t]{2}{*}{ Incorrect } & 2 & 1 & 3 & 2 & 1 & 3 & 4 & 2 & 6 \\
\hline & 0.895 & 0.944 & 0.919 & 0.778 & 0.909 & 0.850 & 0.857 & 0.933 & 0.895 \\
\hline
\end{tabular}




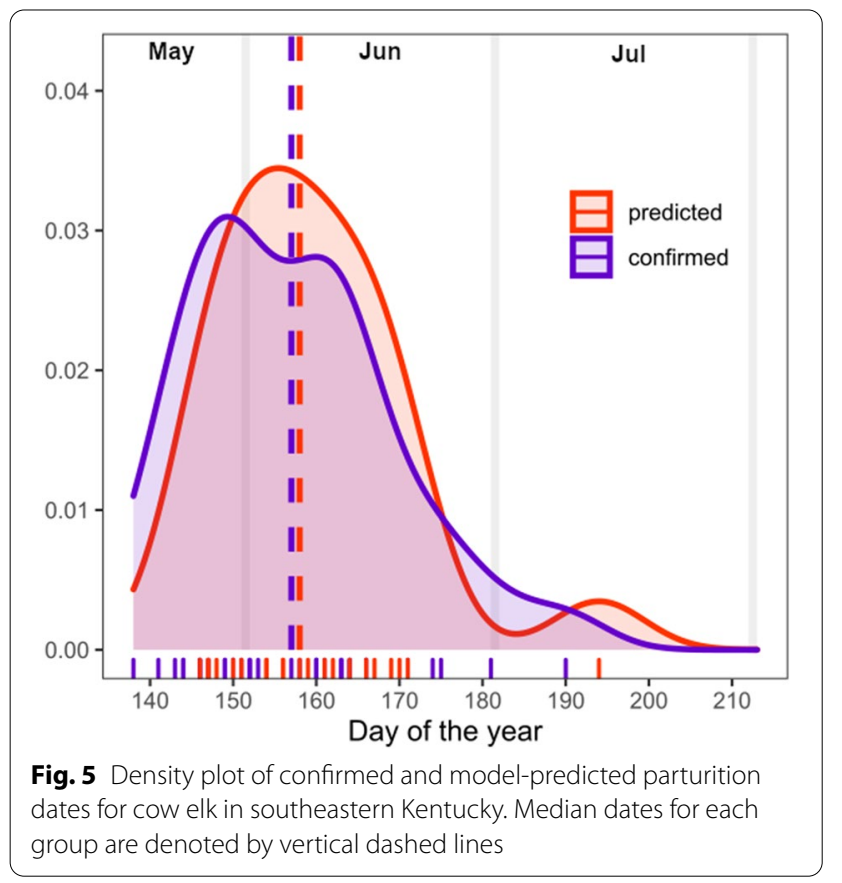

success in Lotek collars, but it is likely that low success in both collar types is also related to terrain and vegetation cover. The influence of these factors on GPS collar fix acquisition and location accuracy are wellestablished [83, 84], and it is probable that landscape characteristics across the KERZ led to missed satellite transmissions and thus data gaps. This could lead to bias in inference of reproductive success across a gradient of habitat types, as Kentucky elk exhibit temporal and individual variation in their selection of forest cover ([85], N. Hooven, University of Kentucky, unpublished data). While our method of calculating movement metrics overcame some of the limitations of periodic fix failure (e.g., several missed fixes would still allow for calculation of mean step length within a 3-day or 7-day focal window), we were unable to generate complete metrics for every individual across the study period, thus leading to gaps in the predicted probability times series resulting from the RF model. We acknowledge the likelihood that some of these gaps included the day of parturition for Group B and Group $\mathrm{C}$ animals that we classified as non-parturient. DeMars et al. [41] showed that data gaps and lowered fix success limited their inference of parturition and calf loss in caribou, and we concur that missing data likely represents the greatest drawback to any movement-based approach. However, fix rate itself only limits the types and temporal scales of movement metrics that can be

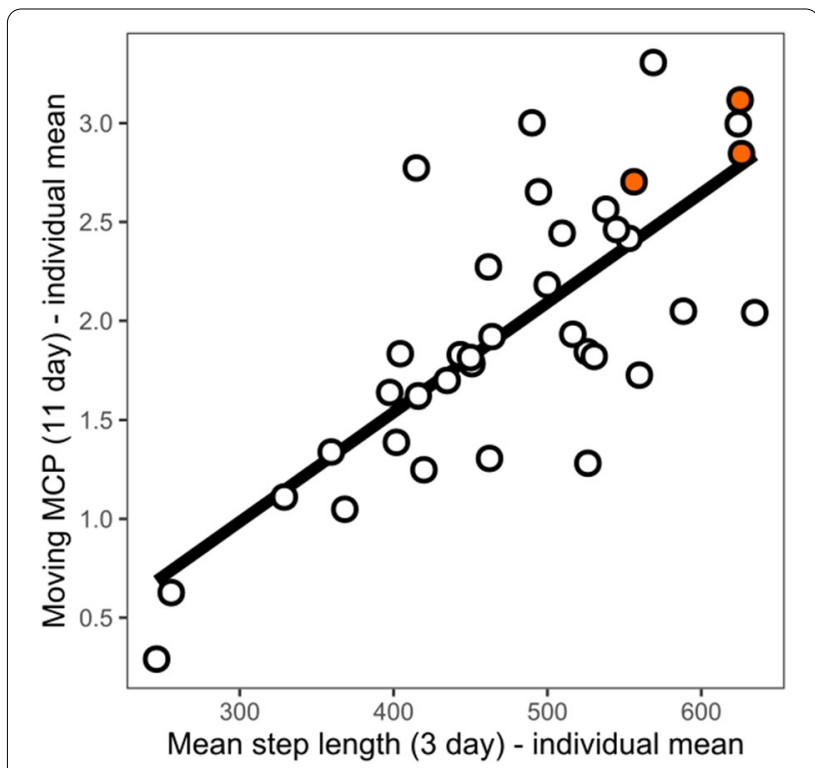

Fig. 6 Relationship between the mean 3-day step length and 11-day MCP used to train the model. Hollow circles are individuals that we correctly classified as parturient, and filled circles are individuals that were misclassified by our approach

used for inference, as we have shown here that a 13-h fix rate is sufficient to identify parturition events in elk if appropriate metrics are chosen.

The second limitation is that individual variation in movement and space use during our study period led to lower model accuracy and thus likely increased misclassification among individuals with unknown parturition status. Wide individual variation in movement behavior [86-89] and space use [90-93] is common across large mammal taxa. We observed a gradient of behavioral types among individuals in our study with regard to the three movement/space use metrics used as predictor variables in our RF model (Additional file 1: Fig. S1). We also documented a correlation between mean 3-day step length and 11-day moving MCP across the study period for elk in our training set (Pearson's correlation; $\rho=0.758$; $d f=35 ; p<0.001$ ), with misclassified individuals tending to move greater distances and use more space than average (Fig. 6). We suggest that this correlation represents a behavioral syndrome in Kentucky elk, demonstrating a gradient of movement behavioral types from "sedentary" to "restless". For our training set, this "restless" behavior likely contributed to misclassification of parturition status. Individuals that exhibit more restlessness may be less likely to contract their movements/space use as severely or for as long as most individuals in the population, making our population-based method less accurate for inferring parturition status among these individuals. 
Because we monitored several cows across both years (Group C cows), we were able to assess how consistency in movement behavior along the "sedentary"-"restless" continuum may contribute to classification as parturient or non-parturient. We documented high repeatability across three movement-based predictors for cows with agreeing statuses in both years, while both step length metrics were not repeatable in cows with disagreeing statuses (Fig. 7; Additional file 1: Table S5). We suggest that behavioral plasticity within individuals may also complicate inference when using movement-based methods, especially when monitoring individuals across multiple years. In our study, because "restless" behavior was related to classification false negatives (Fig. 7), individuals switching behavioral types likely contributes to underestimation of reproductive success using our approach.

Other researchers have attempted to minimize the effects of behavioral variation by fitting individual-based models. DeMars et al. [41] applied both populationbased and individual-based movement models to relocation data in order to infer parturition and calf loss, but application of their methods have seen mixed results in the literature $[45,50]$. While examining movement metrics individually can potentially overcome variation inherent in wild populations, the DeMars individualbased method still assumes that marked changes in step length are indicative of parturition and calf loss. Identification of break points or changes in movement data time series has been used in other ungulate taxa [52, 77] but also suffers from the same limitation that not all individuals exhibit the expected movement pattern. Similarly, our RF classification of focal days approach assumes that all individuals contract their movements in a predictable way, but in practice there are likely to be outlying individuals for which any movement-based methodology may fail to accurately classify. It is possible that by identifying which individuals exhibit movement behaviors that deviate strongly from the population mean, researchers can determine in which situations classification rules may need to be modified to increase accuracy.

A third limitation to our approach is our compression of several vital rates into one. Here we estimate both parturition success (fetal survival) and first-week neonatal survival because of the limitations of our GPS collars. With a finer fix rate, it may be possible to identify parturition itself without associating subsequent movements (e.g., our inclusion of the sl.post7 variable), but we considered a 13-h rate to be too coarse to do so. Also, with our often-low fix acquisition success, widening the temporal periods during which we calculated our movement metrics (3 days, 7 days, and 11 days) likely overcame some missing data problems. Thus, we considered a "success" in our study to be when a cow gave live birth and

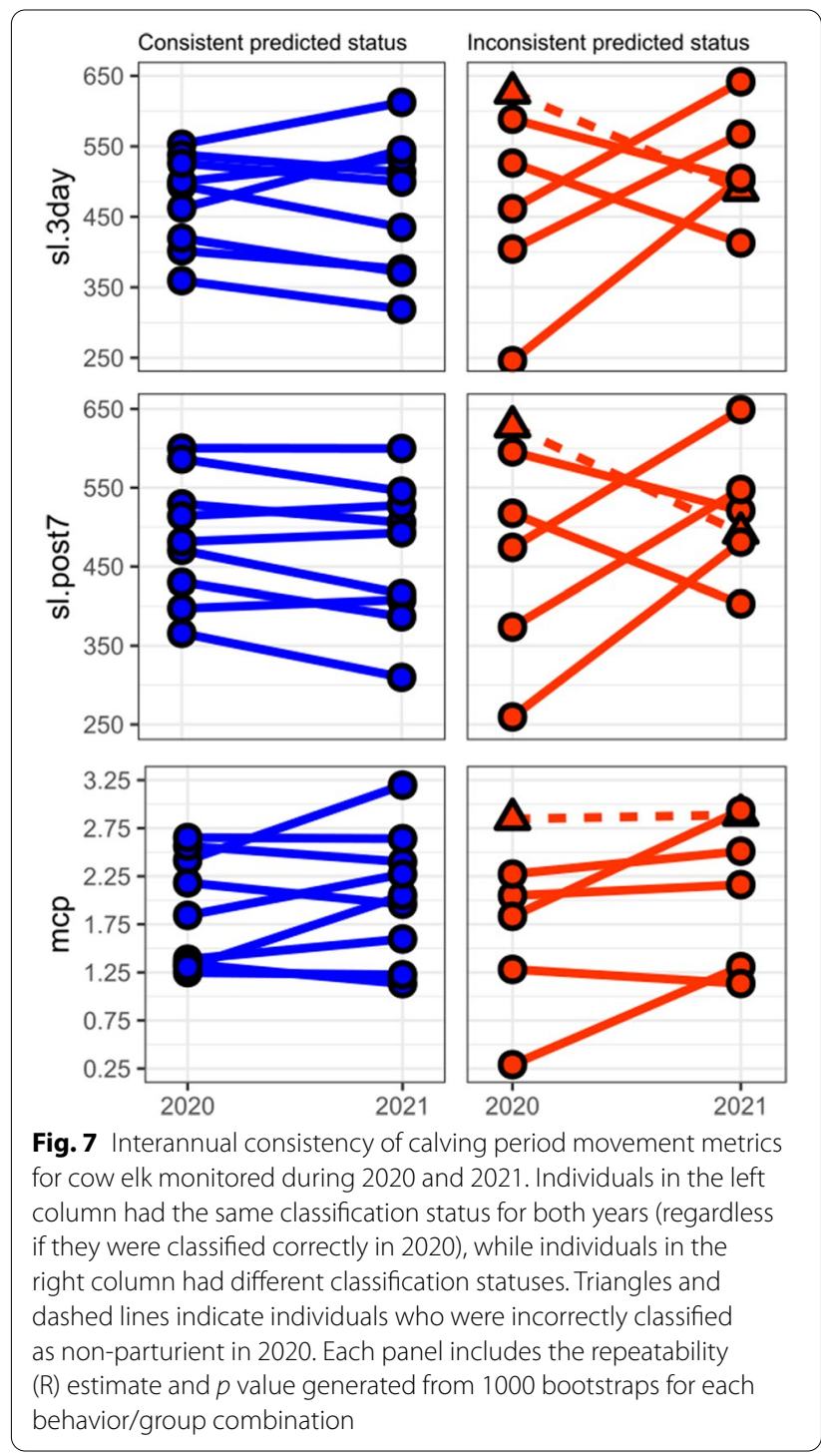

reared her calf to a week old, as movements/space use tended to be contracted within 10 days post-parturition in cows with surviving calves (Fig. 2). Indeed, the sl.post7 variable was the most important in classifying a focal day as one during which parturition occurred in our RF model, suggesting that dropping it from analysis would lead to the model being less accurate. While the inclusion of this variable constrains prediction to cows whose calf survives through the first week, it may be useful to estimate first-week neonatal survival along with fetal survival in this system. The early neonatal period is critical for most ungulate species, with neonates tending to experience the highest mortality within the first $2-4$ weeks [26, $27,42,94]$. We documented five calf mortalities within 1 week of parturition in our study and only two others through August across both years, suggesting that early 
calf mortality is heightened in Kentucky elk as well. In the future, these estimates could complement summer and annual calf survival estimates derived from a concurrent calf collaring and telemetry study in Kentucky (K. Williams, University of Kentucky, unpublished data) and be used in systems where VITs and high-feature GPS telemetry may be cost-prohibitive. Because our measure of success represents a condensation of multiple vital rates, it is similar to an age ratio derived from visual surveys [24, 25 ], and simultaneously estimates the combined effect of fetal survival and early neonatal survival. In addition, our Group $\mathrm{C}$ testing set lacks mid-winter pregnancy data and thus we likely underestimated success among these individuals. However, this demonstrates how our measure of success may be used for future animals in that are monitored for multiple years or past animals for which pregnancy data are also unavailable.

Lastly, our movement-based approach is unable to identify parturition promptly enough to aid in neonate capture, and thus it is not a direct alternative to using VITs when the study objective is collaring neonates. Several researchers have examined GPS relocation data to infer parturition and capture neonates on the ground $[43,75]$ as well as identify calving habitat $[47,48]$, but all used a relatively fine fix rate (one fix every $\leq 4 \mathrm{~h}$ ). Also, as we did not consistently observe long distance preparturition movements in our study animals, identifying parturition based upon visual observation alone would have been difficult during the first few days of life for the neonate. Our wide temporal periods over which we calculated movement metrics also make fine-scale inference difficult; as such we recommend that our approach is best suited for retroactive inference of reproductive success.

Despite these limitations, we believe that the advantages of our approach should warrant consideration by ungulate management programs. By choosing simple movement metrics readily calculated in commonly used $\mathrm{R}$ packages ('amt' and 'adehabitatHR'), generating predictor variables for use in similar analyses is straightforward and adaptable (Additional file 2: see "user-friendly" $\mathrm{R}$ workflow). We have demonstrated that relocationderived metrics are predictive of reproductive success in elk without the inclusion of other biologged or landscape data, and further work should address applicability in other regions and taxa. The RF classification framework for prediction is flexible and robust to non-linear relationships [54] and is also straightforward to run in the $\mathrm{R}$ environment, making it useful and accessible to managers with a rudimentary understanding of $R$ programming.

We also consider the increased sample size resulting from our approach to be a major advantage. The natallinked collar packages we deployed are costly $(\sim 2860)$ and while they provide remote notification of parturition and offspring mortality events, virtually eliminating the need for on-the-ground monitoring via VHF telemetry or resighting, agencies are may not be financially capable of deploying large sample sizes of these units for more than a few consecutive years. Until the cost of this technology decreases, ungulate management programs without targeted funding specifically for research on reproductive and juvenile survival rates may need to rely on budget telemetry devices used for general monitoring of adult survival and spatial distribution. In Kentucky, our approach can easily be applied to future GPS relocation data, and when coupled with mid-winter pregnancy information can lead to annual monitoring of calving date and some components of reproductive success. Also, infrequent fix rates increase collar battery life, allowing for longer monitoring of individual animals and characterization of individual reproductive success in subsequent years. While our model-derived success rates $(38.9 \%$ and $57.9 \%$ for confirmed pregnant cows and unconfirmed cows, respectively) probably underestimated the proportion of cows rearing a calf to a week old, they were substantially lower than our VIT-derived rate $(85.1 \%)$, suggesting that fetal and early calf mortality may represent a considerable subtraction from reproductive potential in this population. We stress the further need for understanding how these rates contribute to population dynamics as well as what intrinsic and extrinsic factors may influence them.

\section{Conclusions}

Acquiring information about population parameters is necessary for sustainable harvest and habitat management, yet collaring programs are often only financially equipped to monitor adult survival. Given the expensive nature of capturing, collaring, and monitoring wild ungulates, it is critical that wildlife managers obtain the highest quality and quantity of data from expensive and time-consuming capture efforts. Our use of low-fix rate GPS relocations to generate simple movement metrics and inform a predictive model of reproductive success presents an opportunity for wildlife management agencies to harness data with a coarse temporal resolution to answer questions related to neonate production and survival while monitoring animals for as long as possible. We posit that coarse fix rates are not a barrier to extracting reproductive data, although fix success and individual behavior may limit inference. More direct methods such as VITs and neonate telemetry still provide the most unbiased estimates of these vital rates, and it is important for managers to update estimates of pregnancy, fetal survival, and juvenile survival regularly. However, for programs that either have historical GPS data or are currently monitoring females with GPS 
collars, movement-based methods may aid in expanding estimates of reproductive success no matter the temporal resolution of the data collected.

\author{
Abbreviations \\ GPS: Global Positioning System; KDFWR: Kentucky Department of Fish and \\ Wildlife Resources; KERZ: Kentucky Elk Restoration Zone; MCP: Minimum con- \\ vex polygon; RF: Random forest; SE: Standard error; UHF: Ultra-high frequency; \\ VHF: Very-high frequency; VIT: Vaginal implant transmitter.
}

\section{Supplementary Information}

The online version contains supplementary material available at https://doi. org/10.1186/s40317-022-00276-0.

Additional file 1: Table S1. Studies that used GPS telemetry to identify parturition events in ungulates $(n=20)$. Table S2. Mean $(\bar{x})$, standard error (SE), maximum (Max.), and minimum (Min.) 3-day average step length (sl.3 day) for training set cows $(n=37)$ by days from confirmed parturition. Table S3. Confirmed and predicted parturition dates for cow elk included in the training set (those whose data were used to fit the random forest model), along with deviation from the confirmed date. Only cows we classified as parturient using our predicted probability threshold decision rule are included. Table S4. Confirmed parturition dates for cows either misclassified as non-parturient by our approach or for those not included in the random forest model and predicted parturition dates for testing set (Group B and C) cows identified as parturient using our approach. Table S5. Repeatability (R) of the three predictor variables among elk initially collared in 2020 that were monitored in 2021 ( $n=15)$. "Agreement" refers to individuals whose predicted parturition status was the same in both years $(n=9)$, and "disagreement" refers to individuals whose status differed between years $(n=6)$. Figure S1. Detail of individual 3-day average step lengths from 21 days before parturition to 6 days after for training set cows. Green points are individual values and black horizontal lines are training set means. Figure S2. Individual variation in movement/ space use metrics across the study period for cow elk. Blue points indicate individuals that were predicted parturient, while red points are individuals predicted non-parturient.

Additional file 2: User-friendly $\mathrm{R}$ workflow for using low-fix rate GPS telemetry to determine ungulate reproductive success. RMarkdown document detailing the basic workflow preparing data, generating movement metrics, and producing RF predictions.

\section{Acknowledgements}

We would like to thank our reviewers for providing feedback that improved this manuscript. We also thank the Department of Forestry and Natural Resources at the University of Kentucky (UK) for logistical support and UK's Robinson Center for Appalachian Resource Sustainability for providing field housing. We also want to acknowledge the staff and volunteers who assisted in the field with elk capture and data collection, especially: C. Casey, J. Fusaro, K. Sams, T. Curry, D. Brewster, Z. Hahn, J. Lane, E. Evers, K. Davis, S. Maywald, A. Riggs, J. Wissmann, P. Clements, K. Bosch, D. Yancy, and M. Peterson. Finally, we thank the landowners and managers for allowing us to capture elk on their properties across the KERZ.

\section{Authors' contributions}

$\mathrm{NDH}$ wrote the manuscript with support from KEW, MTS, and JJC. NDH, KEW JRM, GJ, MTS, and JJC developed the study design. NDH performed spatial data processing and statistical analyses. NDH, KEW, JTH, JRM, RDC, and GJ contributed to field data collection. JTH, GJ, MTS, and JJC obtained funding. All authors read and approved the final manuscript.

\section{Funding}

Funding for elk capture and telemetry was primarily funded by PittmanRobertson federal aid administered by KDFWR and supplemented by the U.S. Department of Agriculture McIntire-Stennis program (Project \#1021936).
NDH was supported by a teaching assistantship through the Department of Forestry and Natural Resources at the University of Kentucky during part of this study.

\section{Availability of data and materials}

The GPS collar-generated dataset analyzed in this study is not publicly available due to potential ethical implications of access to raw relocation data, but are available from the corresponding author on reasonable request. Other datasets used in this study are available in the Zenodo repository, http://doi. org/10.5281/zenodo.5608744, and all R scripts are archived on GitHub, https:// github.com/nhooven/elk-repro-success.

\section{Declarations}

\section{Ethics approval and consent to participate}

We received prior approval to conduct elk captures by the Institutional Animal Care and Use Committee of the University of Kentucky (protocol \#2019-3382), and all capture methodology followed guidelines for the use of wild mammals in research outlined by the American Society of Mammalogists [95].

\section{Consent for publication}

Not applicable.

\section{Competing interests}

The authors declare that they have no competing interests.

\section{Author details}

${ }^{1}$ Department of Forestry and Natural Resources, University of Kentucky, Lexington, KY, USA. ${ }^{2}$ Deer and Elk Program, Kentucky Department of Fish and Wildlife Resources, Frankfort, KY, USA.

Received: 29 October 2021 Accepted: 21 January 2022

Published online: 07 February 2022

\section{References}

1. Johnson HE, Mills LS, Stephenson TR, Wehausen JD. Population-specific vital rate contributions influence management of an endangered ungulate. Ecol Appl. 2010;20:1753-65.

2. Eacker DR, Lukacs PM, Proffitt KM, Hebblewhite M. Assessing the importance of demographic parameters for population dynamics using Bayesian integrated population modeling. Ecol Appl. 2017;27:1280-93.

3. Tatman NM, Liley SG, Cain JW, Pitman JW. Effects of calf predation and nutrition on elk vital rates. J Wildl Manag. 2018;82:1417-28.

4. Frederiksen M, Lebreton J-D, Pradel R, Choquet R, Gimenez O. Identifying links between vital rates and environment: a toolbox for the applied ecologist. J Appl Ecol. 2014;51:71-81.

5. Desforges J, Marques GM, Beumer LT, Chimienti M, Hansen LH, Pedersen $\mathrm{SH}$, et al. Environment and physiology shape Arctic ungulate population dynamics. Glob Chang Biol. 2021;27:1755-71.

6. Bergman EJ, Bishop CJ, Freddy DJ, White GC, Doherty PF. Habitat management influences overwinter survival of mule deer fawns in Colorado. J Wildl Manag. 2014;78:448-55

7. Peters DC, Brooke JM, Tanner EP, Unger AM, Keyser PD, Harper CA, et al. Impact of experimental habitat manipulation on northern bobwhite survival. Jour Wild Manag. 2015:79:605-17.

8. Lindzey FG, Van Sickle WD, Laing SP, Mecham CS. Cougar population response to manipulation in southern Utah. Wild Soc Bull. 1992;20:224-7.

9. Servanty S, Gaillard J-M, Ronchi F, Focardi S, Baubet É, Gimenez O. Influence of harvesting pressure on demographic tactics: implications for wildlife management: harvesting and demographic tactics. J Appl Ecol. 2011;48:835-43.

10. Slabach BL, Hast JT, Murphy SM, Bowling WE, Crank RD, Jenkins G, et al. Survival and cause-specific mortality of elk Cervus canadensis in Kentucky, USA. Wildl Biol. 2018;2018:wlb.00459.

11. Wisdom MJ, Mills LS, Doak DF. Life stage simulation analysis: estimating vital-rate effects on population growth for conservation. Ecology. 2000;81:628-41. 
12. Raithel JD, Kauffman MJ, Pletscher DH. Impact of spatial and temporal variation in calf survival on the growth of elk populations. J Wildl Manag. 2007;71:795-803.

13. DeVivo MT, Cottrell WO, DeBerti JM, Duchamp JE, Heffernan LM, Kougher JD, et al. Survival and cause-specific mortality of elk Cervus canadensis calves in a predator rich environment. Wildl Biol. 2011;17:156-65.

14. Fonseca C, da Silva AA, Alves J, Vingada J, Soares AMVM. Reproductive performance of wild boar females in Portugal. Eur J Wildl Res. 2011:57:363-71.

15. Peterson ME, Anderson CR, Northrup JM, Doherty PF. Reproductive success of mule deer in a natural gas development area. Wildl Biol. 2017;2017:wlb.00341.

16. Bowyer RT, Stewart KM, Bleich VC, Whiting JC, Monteith KL, Blum ME, et al. Metrics of harvest for ungulate populations: misconceptions, lurking variables, and prudent management. Alces. 2020;56:15-38.

17. Sand $\mathrm{H}$. Life history patterns in female moose (Alces alces): the relationship between age, body size, fecundity and environmental conditions. Oecologia. 1996;106:212-20.

18. Greer KR, Hawkins WW. Determining pregnancy in elk by rectal palpation. J Wildl Manag. 1967;31:145-9.

19. Follis TB, Spillett JJ. Winter pregnancy rates and subsequent fall cow/calf ratios in elk. J Wildl Manag. 1974;38:789-91.

20. Willard ST, Sasser RG, Gillespie JC, Jaques JT, Welsh TH Jr, Randel RD. Methods for pregnancy determination and the effects of body condition on pregnancy status in Rocky Mountain elk (Cervus elaphus nelsoni). Theriogenology. 1994;42:1095-102.

21. Wittmer HU, McLellan BN, Seip DR, Young JA, Kinley TA, Watts GS, et al. Population dynamics of the endangered mountain ecotype of woodland caribou (Rangifer tarandus caribou) in British Columbia, Canada. Can J Zool. 2005;83:407-18.

22. Piasecke JR, Bender LC, Schmitt SM. Factors affecting pregnancy in free-ranging elk, Cervus elaphus nelsoni, in Michigan. Can Field Nat. 2009;123:230-5.

23. Bonenfant C, Gaillard J-M, Klein F, Hamann J-L. Can we use the young: female ratio to infer ungulate population dynamics? An empirical test using red deer Cervus elaphus as a model. J Appl Ecol. 2005;42:361-70.

24. Harris NC, Kauffman MJ, Mills LS. Inferences about ungulate population dynamics derived from age ratios. J Wildl Manag. 2008;72:1143-51.

25. DeCesare NJ, Hebblewhite M, Bradley M, Smith KG, Hervieux D, Neufeld L. Estimating ungulate recruitment and growth rates using age ratios. J Wildl Manag. 2012;76:144-53.

26. Barber-Meyer SM, Mech LD, White PJ. Elk calf survival and mortality following wolf restoration to Yellowstone National Park. Wildl Monogr. 2008;169:1-30.

27. White CG, Zager P, Gratson MW. Influence of predator harvest, biological factors, and landscape on elk calf survival in Idaho. J Wildl Manag. 2010;74:355-69.

28. Pinard V, Dussault C, Ouellet J-P, Fortin D, Courtois R. Calving rate, calf survival rate, and habitat selection of forest-dwelling caribou in a highly managed landscape. J Wildl Manag. 2012;76:189-99.

29. Carstensen M, DelGiudice GD, Sampson BA. Using doe behavior and vaginal-implant transmitters to capture neonate white-tailed deer in north-central Minnesota. Wildl Soc Bull. 2003;31:634-41.

30. Barbknecht AE, Fairbanks WS, Rogerson JD, Maichak EJ, Meadows LL. Effectiveness of vaginal-implant transmitters for locating elk parturition sites. J Wildl Manag. 2009;73:144-8.

31. Dion JR, Haus JM, Rogerson JE, Bowman JL. An initial performance review of vaginal implant transmitters paired with GPS collars. Anim Biotelemetry. 2019;7:22.

32. Gilbert SL, Lindberg MS, Hundertmark KJ, Person DK. Dead before detection: addressing the effects of left truncation on survival estimation and ecological inference for neonates. Methods Ecol Evol. 2014;5:992-1001.

33. Chitwood MC, Lashley MA, DePerno CS, Moorman CE. Considerations on neonatal ungulate capture method: potential for bias in survival estimation and cause-specific mortality. Wildl Biol. 2017;2017:wlb.00250.

34. Bishop CJ, White GC, Lukacs PM. Evaluating dependence among mule deer siblings in fetal and neonatal survival analyses. J Wildl Manag. 2008;72:1085-93.

35. Wells RS, Smith CR, Sweeney JC, Townsend Fl, Fauquier DA, Stone R, et al. Fetal survival of common bottlenose dolphins (Tursiops truncatus) in Sarasota Bay. Florida Aquat Mamm. 2014;40:252-9.
36. Verme LJ. Assessment of natal mortality in Upper Michigan deer. J Wildl Manag. 1977;41:700-8.

37. Kirkpatrick JF, Turner JW. Compensatory reproduction in feral horses. J Wildl Manag. 1991;55:649-52.

38. Testa JW, Adams GP. Body condition and adjustments to reproductive effort in female moose (Alces alces). J Mammal. 1998;79:1345-54.

39. Barratclough A, Gomez F, Morey J, Meegan J, Parry C, Schwacke L, et al. Biochemical and hematological biomarkers of reproductive failure in bottlenose dolphins Tursiops truncatus. Dis Aquat Org. 2021;144:197-208.

40. Bishop CJ, Anderson CR, Walsh DP, Bergman EJ, Kuechle P, Roth J. Effectiveness of a redesigned vaginal implant transmitter in mule deer. J Wildl Manag. 2011;75:1797-806.

41. DeMars CA, Auger-Méthé M, Schlägel UE, Boutin S. Inferring parturition and neonate survival from movement patterns of female ungulates: a case study using woodland caribou. Ecol Evol. 2013;3:4149-60.

42. Patterson BR, Benson JF, Middel KR, Mills KJ, Silver A, Obbard ME. Moose calf mortality in central Ontario, Canada. J Wildl Manag. 2013;77:832-41.

43. Peterson ME, Anderson CR Jr, Alldredge MW, Doherty PF Jr. Using maternal mule deer movements to estimate timing of parturition and assist fawn captures. Wildl Soc Bull. 2018;42:616-21.

44. Cameron MD, Joly K, Breed GA, Parrett LS, Kielland K. Movement-based methods to infer parturition events in migratory ungulates. Can J Zool. 2018;96:1187-95.

45. Marchand P, Garel M, Morellet N, Benoit L, Chaval Y, Itty C, et al. A standardised biologging approach to infer parturition: an application in large herbivores across the hider-follower continuum. Methods Ecol Evol. 2021;12:1017-30.

46. Testa JW, Becker EF, Lee GR. Movements of female moose in relation to birth and death of calves. Alces. 2000;36:155-62.

47. McGraw AM, Terry J, Moen R. Pre-parturition movement patterns and birth site characteristics of moose in northeast Minnesota. Alces. 2014;50:93-103.

48. Melin M, Matala J, Pusenius J, Packalen T. Calving and post-calving habitat use of female moose in two contrasting landscapes. Wildl Biol. 2019;2019:wlb.00569.

49. Long RA, Kie JG, Bowyer RT, Hurley MA. Resource selection and movements by female mule deer (Odocoileus hemionus): effects of reproductive stage. Wildl Biol. 2009;15:288-98.

50. Bonar M, Ellington EH, Lewis KP, Vander WE. Implementing a novel movement-based approach to inferring parturition and neonate caribou calf survival. PLoS ONE. 2018;13:e0192204.

51. Vore JM, Schmidt EM. Movements of female elk during calving season in northwest Montana. Wildl Soc Bull. 2001;29:720-5.

52. Dzialak MR, Harju SM, Osborn RG, Wondzell JJ, Hayden-Wing LD, Winstead $J B$, et al. Prioritizing conservation of ungulate calving resources in multiple-use landscapes. PLOS ONE. 2011;6:e14597.

53. Hepler JD. Validating a GPS collar-based method to estimate parturition events and calving locations for two barren-ground caribou herds [Thesis]. Fairbanks: University of Alaska; 2019.

54. Valletta JJ, Torney C, Kings M, Thornton A, Madden J. Applications of machine learning in animal behaviour studies. Anim Behav. 2017;124:203-20.

55. Breiman L. Random forests. Mach Learn. 2001:45:5-32.

56. James G, Witten D, Hastie T, Tibshirani R. An introduction to statistical learning with applications in R. 2nd ed. Berlin: Springer; 2021.

57. Berg JE, Reimer J, Smolko P, Bohm H, Hebblewhite M, Merrill EH. Mothers' movements: shifts in calving area selection by partially migratory elk. J Wildl Manag. 2021;85:1476-89.

58. Nobert BR, Milligan S, Stenhouse GB, Finnegan L. Seeking sanctuary: the neonatal calving period among central mountain woodland caribou (Rangifer tarandus caribou). Can J Zool. 2016;94:837-51.

59. KDFWR. 2020-2021 Kentucky Department of Fish and Wildlife Resources elk report. Frankfort: Kentucky Department of Fish and Wildlife Resources; 2020. p. 13.

60. KDFWR. 2015-2030 Kentucky elk management plan. Frankfort: Kentucky Department of Fish and Wildlife Resources; 2015. p. 42.

61. Newell WL. Physiography. Report no.: 1151-H. Virginia: U.S. Geological Survey; 1986. p. 6

62. Larkin JL, Cox JJ, Wichrowski MW, Dzialak MR, Maehr DS. Influences on release-site fidelity of translocated elk. Restor Ecol. 2004;12:97-105. 
63. Thompson MJ, Henderson RE, Lemke TO, Sterling BA. Evaluation of a collapsible clover trap for elk. Wildl Soc Bull. 1989;17:287-90.

64. Wolfe LL, Lance WR, Smith DK, Miller MW. Novel combinations of nalbuphine and medetomidine for wildlife immobilization. J Wildl Dis. 2014:50:951-6.

65. McDermott JR, Leuenberger W, Haymes CA, Clevinger GB, Trudeau JK, Carter TC, et al. Safe use of butorphanol-azaperone-medetomidine to immobilize free-ranging white-tailed deer. Wild I Soc Bull. 2020;44:281-91.

66. Wolfe LL, Fisher MC, Davis TR, Miller MW. Efficacy of a low-dosage combination of butorphanol, azaperone, and medetomidine (BAM) to immobilize Rocky Mountain elk. J Wildl Dis. 2014;50:676-80.

67. VECTRONIC Aerospace. INVENTA wildlife monitoring. https://inventa.vectr onic-wildlife.com/. Accessed 28 Oct 2021.

68. R Core Team. R: a language and environment for statistical computing. Vienna: R Foundation for Statistical Computing; 2019.

69. Lowrey B, Garrott RA, Miyasaki HM, Fralick G, Dewey SR. Seasonal resource selection by introduced mountain goats in the southwest Greater Yellowstone Area. Ecosphere. 2017:8:e01769.

70. Pebesma E, Bivand R, Rowlingson B, Gomez-Rubio V, Hijmans R, Sumner M, MacQueen D, Lemon J, Lindgren F, O'Brien J, O'Rourke J. "sp": classes and methods for spatial data. R package version 1.2-1; 2020.

71. Signer J, Reineking B, Schlägel UE, LaPoint S. "amt": animal movement tools. R package version 0.1.3; 2020.

72. Brook RK. Habitat selection by parturient elk (Cervus elaphus) in agricultural and forested landscapes. Can J Zool. 2010;88:968-76.

73. Bertrand MR, DeNicola AJ, Beissinger SR, Swihart RK. Effects of parturition on home ranges and social affiliations of female white-tailed deer. J Wildl Manag. 1996;60:899-909.

74. Ciuti S, Bongi P, Vassale S, Apollonio M. Influence of fawning on the spatial behaviour and habitat selection of female fallow deer (Dama dama) during late pregnancy and early lactation. J Zool. 2005;268:97-107.

75. Severud WJ, DelGiudice G, Obermoller TR, Enright TA, Wright RG, Forester JD. Using GPS collars to determine parturition and cause-specific mortality of moose calves. Wildl Soc Bull. 2015;39:616-25.

76. Forshee S. Life on the edge: risk of predation drives selection of habitat and survival of neonates in endangered Sierra Nevada bighorn sheep [Thesis]. Missoula: University of Montana; 2018.

77. Nicholson KL, Warren MJ, Rostan C, Mansson J, Paragi TF, Sand H. Using fine-scale movement patterns to infer ungulate parturition. Ecol Indic. 2019;101:22-30.

78. Calenge $C$. "adehabitatHR": home range estimation. $\mathrm{R}$ package version $0.4 .16 ; 2019$.

79. U.S. Forest Service. USFS tree canopy cover datasets. U.S. Forest Service. https://data.fs.usda.gov/geodata/rastergateway/treecanopycover/. Accessed 8 Oct 2020. 2016.

80. Hijmans RJ. "raster": geographic data analysis and modelling. R package version 3.0-12; 2020.

81. Breiman L, Cutler A, Liaw A, Wiener M. "randomForest": Breiman and Cutler's random forests for classification and regression. $R$ package version 4.6-12; 2018.

82. Stoffel MA, Nakagawa S, Schielzeth H. "rptR": repeatability estimation for Gaussian and non-Gaussian data. R package version 0.9.22; 2019.

83. Cain JW, Krausman PR, Jansen BD, Morgart JR. Influence of topography and GPS fix interval on GPS collar performance. Wild Soc Bull. 2005;33:926-34

84. Vance JA, Jachowski DS, Boynton AC, Kelly MJ. Importance of evaluating GPS telemetry collar performance in monitoring reintroduced populations. Wildl Soc Bull. 2017:41:729-35.

85. Hast JT. Vital rates and habitat selection of bull elk (Cervus canadensis nelsoni) in southeast Kentucky [Dissertation]. Lexington: University of Kentucky; 2019.

86. Mueller T, Olson KA, Dressler G, Leimgruber P, Fuller TK, Nicolson C, et al. How landscape dynamics link individual- to population-level movement patterns: a multispecies comparison of ungulate relocation data: population-level movement patterns. Global Ecol Biogeogr. 2011;20:683-94.

87. Hertel AG, Leclerc M, Warren D, Pelletier F, Zedrosser A, Mueller T. Don't poke the bear: using tracking data to quantify behavioural syndromes in elusive wildlife. Anim Behav. 2019;147:91-104.

88. Hertel AG, Niemelä PT, Dingemanse NJ, Mueller T. A guide for studying among-individual behavioral variation from movement data in the wild. Mov Ecol. 2020;8:30
89. Webber QM, Laforge MP, Bonar M, Robitaille AL, Hart C, Zabihi-Seissan $\mathrm{S}$, et al. The ecology of individual differences empirically applied to spaceuse and movement tactics. Am Nat. 2020;196:708721.

90. Anderson DP, Forester JD, Turner MG, Frair JL, Merrill EH, Fortin D, et al. Factors influencing female home range sizes in elk (Cervus elaphus) in North American landscapes. Landsc Ecol. 2005;20:257-71.

91. van Beest FM, Rivrud IM, Loe LE, Milner JM, Mysterud A. What determines variation in home range size across spatiotemporal scales in a large browsing herbivore? J Anim Ecol. 2011;80:771-85.

92. Dechen Quinn AC, Williams DM, Porter WF. Landscape structure influences space use by white-tailed deer. J Mammal. 2013;94:398-407.

93. Mangipane LS, Belant JL, Hiller TL, Colvin ME, Gustine DD, Mangipane BA, et al. Influences of landscape heterogeneity on home-range sizes of brown bears. Mamm Biol. 2018;88:1-7.

94. Eacker DR, Hebblewhite M, Proffitt KM, Jimenez BS, Mitchell MS, Robinson HS. Annual elk calf survival in a multiple carnivore system. J Wildl Manag. 2016;80:1345-59.

95. Sikes RS, Bryan JA II, Byman D, Danielson BJ, Eggleston J, Gannon MR, et al. 2016 guidelines of the American Society of Mammalogists for the use of wild mammals in research and education. J Mammal. 2016;97:663-88.

\section{Publisher's Note}

Springer Nature remains neutral with regard to jurisdictional claims in published maps and institutional affiliations.

Ready to submit your research? Choose BMC and benefit from:

- fast, convenient online submission

- thorough peer review by experienced researchers in your field

- rapid publication on acceptance

- support for research data, including large and complex data types

- gold Open Access which fosters wider collaboration and increased citations

- maximum visibility for your research: over $100 \mathrm{M}$ website views per year

At BMC, research is always in progress.

Learn more biomedcentral.com/submissions 